\title{
Teaching Antonyms to Arabic-Speaking EFL Learners
}

\author{
https://doi.org/10.3991/ijet.v14i18.11198 \\ Abdel Rahman Mitib Altakhaineh ${ }^{(\varpi)}$ \\ Al Ain University of Science and Technology, Abu Dhabi, UAE \\ abdelrahman.takhaine@aau.ac.ae \\ Maram H. Hajjo \\ Al-Andalus Private Academy, Al Ain, UAE
}

\begin{abstract}
This study investigates the impact of different teaching techniques, e.g. projecting pictures using an overhead projector and the traditional way of teaching, in improving Arabic-speaking EFL learners' production of antonyms in English. A production test was administered, including 20 pairs of antonyms, to assess the students' knowledge of English antonyms before the instructional intervention. To this end, 40 grade six students were divided into two groups: treatment and control. After the instructional intervention, a Pictionary Test was implemented, including 10 pairs of antonyms as post-test to determine if projecting pictures via an overhead projector can be an effective technique in increasing students' production of English antonyms. The results showed that the number of accurate answers provided by the treatment group (who were taught using pictures via overhead projector) was higher than that provided by the control group (who were taught via the traditional method). This suggests that the former teaching technique may have played an important role in their performance on the test. It can be concluded that teaching via overhead projector with pictures seems to be an effective instructional intervention in teaching English antonyms.
\end{abstract}

Keywords-Linguistics, semantics, antonyms, teaching techniques, technology in teaching, Arabic-speaking EFL learners

\section{$1 \quad$ Introduction}

Studying sense/lexical relations between words is one of the most significant topics in Applied Linguistics, specifically to those who are interested in teaching the most common ones. i.e. synonymy, antonymy, homonymy among others. One of the most important lexical relations is antonymy, which is a sense relation between words with opposite meanings. As believed in [1], human thinking and language are closely related; thus the significance of antonyms in human thinking processes is inevitably reflected in language. This means that there are numerous numbers of contrasting lexical items, antonyms, in human languages. Learning word opposition is a very useful tool for Arabic-speaking EFL learners for both speaking and writing. Thus, the acquisition of antonyms facilitates learning new words. This acquisition also helps EFL 
learners to understand the main idea of text or speech as well as to be precise in writing. Giving a list of antonyms would be one of the most effective strategies to learn new words, since it accelerates the process of learning lexical items and makes the retention of words better and easier. The acquisition of antonym has received much attention in the last decade [2]. Many researchers [3], [4], [5] have focused on the acquisition of antonyms by English-speaking learners. Yet, a few researchers have addressed the acquisition of antonyms by second language learners of English. Consequently, the purpose of this study is to examine one technique in teaching antonyms to Arabic-speaking EFL learners and to determine whether this technique is effective.

\section{Background}

\subsection{What is antonym?}

As defined in [6], antonym is the name for oppositeness relation. Antonym vs. synonym is an example of two lexical units with opposite meaning. It is defined as "a binary relationship between terms with complementary meanings" [7]. For example, male vs. female and husband vs. wife are complementary antonym. Furthermore, Antonyms are opposite pairs that

- Are semantically incompatible; they cannot simultaneously refer to the same thing

- Are in a relation of minimal semantic difference [8]. The example tall vs. short which illustrates that the human being cannot be tall and short concurrently. However, as stated in [5] that without specific contextual information to the contrary, blue and red are incompatible but not antonymous since they contrast with other colours (e.g., green or yellow) at the same taxonomic level. So, antonyms are lexical units that have the same word classes with opposite meaning such as tall vs. short (adjective / adjective) and reject vs. accept (verb/verb).

As noted in [9], antonym relations are more central to the adjective classes than to other classes. This means that various parts of speech can be used as antonyms such as nouns, e.g. prey/predator, verbs, e.g. push vs. pull and adverbs, e.g. carefully vs. carelessly. Nevertheless, adjective class is the most widely used antonyms among other classes.

Structurally, antonyms can be divided into root antonyms i.e., antonyms of different roots, e.g. happy vs. sad, and derivational antonyms i.e., antonyms of the same root, e.g. happy vs. unhappy. Similarly, we compare in this study pairs of antonyms with distinct lexical roots and those derived by affixation, i.e., lexical and morphological antonyms, e.g., small/large and happy/ unhappy respectively [10].

\subsection{Previous studies on the importance of pictures in teaching vocabulary and the acquisition of sense relations and}

As stated in [11] Dual Coding Theory (DCT) emphasized the importance of imagery in the cognitive process of comprehending words and their meanings. Similarly, 
using visual aids, and demonstration help learners in acquiring new vocabulary, because "our memory for objects and pictures is very reliable and visual techniques can act as cues for remembering words" [12].

With regard to the acquisition of new vocabulary, it is stated in [13] that many factors determine the easiness and difficulties of a vocabulary it is as much as similarity to L1, similarity to English words already known, connotation and appropriate use respectively. According to the first factor, some lexical items have the same form as well as same meaning to the learner's first language. For example, English cotton and Arabic qutun 'cotton' have the same meaning and form. It is important to note that not all words of the same form and meaning have the same usage in Arabic and English, e.g., English alcohol and Arabic word al-kuhl, 'black powder' probably cause errors - this is the reason that make some words to be called as fake friends. The process of acquiring the second language rapidly, due to the similarities between L1 rules and $\mathrm{L} 2$ rules, is called positive transfer. Thus, the similarity to L1 could confuse the EFL learners rather than facilitate learning new lexical items for them. Another factor is similarity to English words already known. This factor helps EFL students to identify the meaning of unfamiliar words by associating them with English words they already know. For example, learners who know the meaning of the word friendly are able to guess the meaning of the word unfriendly. In addition, EFL learners must understand the connotation of the word in order to overcome the misunderstanding of certain words. Some words have the same literal meaning; whereas, they differ in the inferred meaning, i.e. connotation. Before using the word, EFL learners have to know whether the word has positive or negative connotation to the first language speaker. For instance, confident and proud are positive while egotistical is a negative way of looking at self-confidence as it indicates something that borders on self-centeredness. Therefore, EFL learners have to be careful while using the words with similar meanings because each word conveys a specific attitude. Furthermore, there is another problematic aspect which is using the lexical items correctly, i.e. appropriate use. EFL learners could be able to use the word appropriately if they know that the exact usage of the word is limited to a particular context. For example, the meaning of the word pushing differs from one context to another. The word "pushing" means almost in the following sentence "He is pushing fifty". Elderly people only use former sentence, but young people do not use it as well as they do not say the following sentence "he is pushing there!" [14].

As indicated in [15], the acquisition of antonyms requires knowledge of relationships among words and thus has been fruitfully used as an indicator of both breadth and depth of vocabulary knowledge. In other words, acquiring antonyms could be helpful for non- native learners since it facilitates acquiring a number of vocabulary words. It is noted in [16] that although some words do not have antonyms (for example, tree), the use of polarity in defining words sets clear parameters in meaning. When learners recognize words with opposite meanings, this recognition offers for them easy to understand dimensions and features that cause differences between pair of opposite words. For instance, when the antonym big vs. small is acquired, EFL learners know that the size is the characteristic that differentiates the two words. Also, when the antonym gather vs. disperse is acquired by EFL learners, this example helps 
the learners to know that aggregation is the dimension that makes them opposite. The use of antonyms can be one of the most powerful tools in vocabulary instruction [17].

There are three fundamental types of antonym: contradictories (complementaries), contraries (gradable), and reciprocal (converse) terms [6]. These types are subsets of root antonym. The antonym pairs like girl vs. boy; dead vs. alive considered as contradictories which have no middle ground; The antonym pairs like big vs. small; transparent vs. opaque are classified as contraries that indicate gradations; and the antonym pairs like buy vs. sell; gather vs. disperse are opposite words that have reversal relationship and are known as reciprocal terms.

In contrast, as suggested in [17] drawing a distinction between polar antonyms and scalar antonyms for teaching purposes. The words with opposite meanings such as husband vs. wife; buy vs. sell are categorized as polar antonyms which do not allow intermediate terms. Likewise, one word's assertion completely refuses another word's possibility. Two main types of anonyms, the contradictories and the reciprocals, are regarded as polar antonyms. However, words like gigantic, big, large, small and tiny refer to gradations between extremes and are known as scalar term. This scalar term may be taught through semantic gradient. When the instructor uses this instructional technique, (s)he will ask students to use a gradient to order lexical items from one scale to the other. For example, the instructor draws a line between the word hot and the word cold in order to make the students write tepid and cool on the line which shows the relatedness between the words. It is introduced in [17] that an alphabeticgenerative activity that requires students to use their vocabulary knowledge and a dictionary, thesaurus, or synonym/antonym dictionary. There are a range of steps that the teacher follows in this activity. First, the teacher chooses words that start with the same letter. Then (s)he draws a two-column table that displays antonyms of second language on the first column. Students start completing the table regardless of the availability of references. Five minutes later, the teacher gives them references to facilitate the answer for them. After that, the teacher discusses their answers and explains them. Finally, the students keep the tables as reference in their vocabulary notebooks. For example, the words fail, forbid, forget, fraction and front are chosen by the teacher as target words. Then the teacher shows words like succeed, allow, remember, whole and back to the students. These antonyms are presented without the target words. Thereafter, the teacher tells the students that all target words begin with the letter $f$, so they have to guess these words. The best way to use this activity with children is group work or whole class. On the other hand, the most suitable way for adults to learn the meanings of the words is by providing them with a word list.

Finally, as reported in [18], the acquisition of sense relations, e.g. synonyms, antonyms etc. by Arabic speaking EFL learners has not given due attention in the relevant literature. Consequently, the ability of 40 Saudi EFL learners to produce synonyms and in turn investigate their acquisition of synonymy was examined in [18]. Data was elicited via a translation test. The results demonstrated that the Advanced learners scored higher than their intermediate learners' counterparts. Nonetheless, both groups encountered difficulties in producing English synonyms which were ascribed to lack of awareness of the different shades between the synonyms in English, L1 interference, lack of focus on the acquisition of vocabulary in schools in Saudi Arabia among 
others [18]. It was recommended [18] that more studies are needed to discover methods to facilitate teaching sense relations, e.g. antonymy.

Drawing on the previous literature, it can be suggested that more studies are needed to determine the effective techniques to teach English antonyms to EFL learners, taking into account the importance of acquiring antonyms to enhance the learners' communicative competence. The current study aims to bridge this gap, specifically, by examining the effective technique(s) used to teach English antonyms to Arabicspeaking EFL learners. This study provides answers to the following research questions:

- To what extent can 40 Arabic-speaking EFL learners improve their production of English antonyms using an overhead projector with pictures?

- Do the treatment group A (i.e. using pictures on an overhead projector) perform better than the control group B (i.e. using traditional way of teaching) in learning English antonyms? If yes, how?

\section{$3 \quad$ Methodology}

\subsection{Sample}

The participants of this study are 40 female EFL learners in grade 6 (12 years old) at Al-Andalus Private Academy, Al Ain, UAE. They were chosen due to the fact that, at this grade, EFL learners in the UAE start to learn more difficult antonyms and start using them in real life. The participants are also taught by the second author who knows their level and is familiar with the difficulties these students encounter at this stage. They were divided into two groups: 20 in the treatment group and 20 in the control group. To make sure that the two groups were homogenous, a production test of 20 items was conducted before the experiment took place as a baseline assessment. The items that had not been answered by any of the students were used during the treatment and after in the test. These items were used along with other words during the treatment.

\subsection{The activities}

Group A and Group B had been taught antonyms for one week. Based on their abilities, group A (i.e. treatment group) students were equally divided into 5 sub-groups. The reason for sub-groups is encouraging students to share ideas. In this regard, as reported in [19] that: group work, role playing and interviews ... encourage shy students to participate and discuss their opinions with their classmates instead of only with teachers. Employing various techniques in the classroom also challenges students and caters for diversity in students' learning styles.

These groups were instructed by displaying slides of different pictures via overhead projector. Each slide included two visual images with a word describing one of these images. These groups had to produce the opposite meaning of the word by look- 
ing at the other picture. These pictures were used to prompt answers from the students. When students faced difficulty identifying the opposite meaning of the words through pictures, they were given an iPad to use an online dictionary. During the teaching session, subgroups of 4 students worked on different activities such as antonym matching board, Jigsaw puzzle, antonyms crossword puzzle and Pictionary game, i.e. a guessing word game by drawing the things that we want to know. All these activities consisted of pictures helping the students to expand their knowledge of English antonyms in a fun way.

On the other hand, group B students (i.e. control group) were traditionally instructed for one week and they were also taught in groups. These students were instructed using direct instruction, i.e. lecturing method of teaching. The words were uttered in front of them, and they had to guess the antonyms. When they struggle to guess the antonyms, the teacher wrote the meaning of the words on the whiteboard. During the teaching session, the students were asked to answer a matching worksheet. This worksheet was composed of 10 pairs of antonym without picture cues. The moment the students had difficulty in answering the matching worksheet, they were given printed dictionaries.

\subsection{Data elicitation tool}

A test with picture cues was used to assess the students' knowledge of antonyms. This test was used as pre- and post-test to measure students' improvement in learning antonyms [20] - [21]. The pre-test consisted of 20 pairs of antonym, while the posttest consisted of only10 pairs. At the end of the week, pre-test was conducted before instruction. Ten words that students already knew were eliminated in the post -test resulting in only 10 pairs of opposite words. A week later, the post-test was conducted (see the appendix). The deletion of the ten words from the pre-test was done because the participants obtained correct answers on these items. As such, this increases the reliability of the test.

The pre-test - post-test design was conducted to compare the final post-test results between treatment and controlled groups to determine which teaching technique could be effective in increasing students' learning of English antonyms.

\subsection{SPSS}

A t-test, a common type of statistical test, was used to compare the means scores of the results of the two groups. It has been asserted in [22] that the means of control and treatment group can be assessed by t-test, to determine whether there is a statistically significant difference between the means of two groups.

\section{$4 \quad$ Results and Discussion}

Table 1 shows that there was a statistically significant difference between group A $(M=16.20)$ and group $B(M=12.30)$ since the $p$-value $(0.0001)$ is less than 0.05 . The $t-$ 
test results proved that teaching via overhead projector affected the scores of treatment group. In other words, teaching via overhead projector shows its advantage over the traditional method.

Table 1. T-test results of the effect of treatment on the participants' performance on the post-

test

\begin{tabular}{|l|c|c|c|c|c|}
\hline Group Type & Mean & SD & Df & t value & Sig. \\
\cline { 1 - 3 } Treatment & 16.20 & 1.75 & \multirow{2}{*}{18} & \multirow{2}{*}{4.7885} & 0.0001 \\
\hline Control & 12.30 & 1.89 & & & \\
\hline
\end{tabular}

$\mathrm{P} \geq 0.05$

The acquisition of antonyms was examined in terms of both pictures via overhead projector (treatment group) and the traditional way of teaching (control group). The results obtained from both groups are presented in Table 2.

Table 2. The number of correct answers on the post-test

\begin{tabular}{|l|c|c|}
\hline \multicolumn{1}{|c|}{ Words } & Treatment & Control \\
\hline Dwarf $\times$ Giant & 15 & 10 \\
\hline Apart $\times$ Together & 14 & 11 \\
\hline Coward $\times$ Brave & 18 & 14 \\
\hline Generous $\times$ Selfish & 19 & 13 \\
\hline Asleep $\times$ Awake & 18 & 12 \\
\hline Shallow $\times$ Deep & 14 & 11 \\
\hline Taciturn $\times$ Talkative & 14 & 10 \\
\hline Crooked $\times$ Straight & 12 & 16 \\
\hline Optimistic $\times$ Pessimistic & 19 & 17 \\
\hline Straight $\times$ Curly & 19 & 123 \\
\hline Total & 162 & \\
\hline
\end{tabular}

Table 2 shows that the treatment (162) got more accurate answers than control group (123). This means that the treatment group performed better than the control group. The treatment group's highest correct answers were with the following antonym pairs: brave vs. coward (18), selfish vs. generous (19), awake vs. asleep (18), pessimistic vs. optimistic (19) and curly vs. straight (19). The reason for this could be that these words, especially awake and asleep, are high- frequency words as well as the most commonly used words through regular speech.

Regarding the antonym curly vs. straight (19), most of the students could produce correct answers due to the fact that in Arab societies, many hair stylists can only speak English, so Arabic speaking EFL students frequently use words like curly and straight. Arabic speaking EFL students scored highly on brave vs. coward, selfish vs. generous and pessimistic vs. optimistic since these words are related to Arab customs and culture. Specifically, most students gave correct answer regarding the antonyms brave and coward, for these antonyms are commonly used during a war or fight between tribes. As for, selfish vs. generous, students provided accurate answer on generous because this word is linked to their hospitality, a duty sacred in the Arab socie- 
ties and something Arabs are known for. It could be noticed that the similarity between pessimistic and optimistic may have caused their correct answers. Since pessimistic and optimistic are words with last syllable rhyme which have the same morpheme (-tic) at the end of both words, this similarity helped the students to elicit the answer correctly.

However, it seems that the performance of treatment group and control group regarding together vs. apart, deep vs. shallow, taciturn vs. talkative, and straight vs. crooked was at its lowest, only a few students produced the correct answers correctly. This can be attributed to these antonyms' low frequency in English spoken and written forms taught to grade 6 students. The low number of the sum of the correct answers of together vs. apart might be due to the fact that they do not use English words when they do puzzles since they rarely use English language outside the classroom.

The reason for low number of correctly produced answers on deep vs. shallow is that the students probably would not use it frequently as most swimming trainers as well as lifeguards can speak their mother-tongue language. Therefore, they do not often use deep and shallow in swimming classes.

Similarly, only a few students produced correct answers on the antonyms talkative vs. taciturn. The low correct answer of taciturn may be due to its low frequency in Corpus Contemporary American English (COCA), the frequency of taciturn is 327 in COCA. It can also be attributed to the low frequency of the word taciturn in the material these students study at school.

With respect to straight $v s$. crooked, the low number of correctly produced answers was could be ascribed to the fact that students were not familiar with the word crooked. They were more familiar with the word curve because it is more frequent word, the frequency of curve is 8433 times in COCA, than the word crooked, the frequency of crooked is 3210 times in COCA.

Regarding giant vs. dwarf, the treatment group did better than control group. This could be attributable to the fact that the shown pictures were attractive and had some cues that helped in suggesting the answer. In line with previous studies, pictures connect students' prior knowledge to a new story, and in the process, help them learn new words [12].

The outperformance of the treatment group over the control group was a consequence of the teaching technique. The treatment group relied more on pictures than being spoon-fed to learn antonyms as they could take advantage of the cues in pictures. This result ties well with previous studies [11] Dual Coding Theory (DCT). As stated in [11] that cognition occurs in two independent but connected codes: a verbal code for language and a nonverbal code for mental imagery. Moreover, it is found out in [23] that in the light of increasingly visual nature of communication, visual modalities can be an important part of meaning making in second language learning. Also, as stated in [23] that using verbal contextual analysis to learn new vocabulary is a common educational technique that may not be potent enough to produce an advanced vocabulary. So, it would appear that the pictures interpretation is somewhat stronger in learning antonyms. Besides, as confirmed in [24] that our brain has a great tendency to analyze data in a visual way and even saves the relation between things and information in a visual configuration not in a literal one. 
The items with high scores may show the effectiveness of teaching with pictures rather than the traditional way. All students commented on the usefulness of visual cues (i.e. pictures). The students made the following comments: The pictures were helpful because the moment we saw the picture, we linked it to real situations, animations, films or video games. For example, brave vs. coward reminded the students of the players in Fortnight, a popular video game. In addition, some students stated that they used to forget the words they had learnt quickly, but now they still remember the words because of the mental image. Other students indicated that they linked the shown pictures to certain situation. For example, one student stated that the illustration reminded her of a colleague who made her curly hair straight. The students could not forget this situation as she was surprised by her friend's new hairstyle as it was the first time for her to straighten her hair. Other students said that scenes and actors of a film entitled "Jumanji: Welcome to the Jungle", which they watched during the second school term as extra-curricular activity, were linked to pessimistic vs. optimistic and brave vs. coward in the post-test. Consequently, these pictures made them recall a precise scene in the film.

\section{$5 \quad$ Conclusion and Recommendations}

The main objective of the current study was to examine whether using pictures can have an effect on the production of English antonyms by Arabic-speaking EFL learners. For this purpose, 40 Arabic-speaking EFL learners were divided into two groups: the control group, who was instructed using the traditional method of teaching English antonyms and the treatment group, who was taught English antonyms via projecting pictures on an overhead projector. Following the treatment, a post-test was administered to determine if there was any significant difference between the performance of both groups on English antonyms. The results of Pictionary Test revealed that the treatment group taught using pictures outperformed those taught using traditional technique. These results provide evidence for the positive effects of including visual illustrations in teaching English antonyms. Thus, it is evident that the frequency of the English words and the attractiveness of pictures had a positive impact on the performance of the treatment group. Based on the results of this study, it is recommended that English language teachers use images to help EFL learners to not only learn antonyms, but also synonyms, hyponyms, meronyms and other sense relations. This will help EFL learners to improve their vocabulary and by extension promote their proficiency level of English.

\section{$6 \quad$ References}

[1] Gao, C., \& Zheng, Q. (2014). A Linguistic Study of Antonymy in English Texts. Journal of Language Teaching \& Research, 5(1). https://doi.org/10.4304/jltr.5.1.234-238

[2] Schmidt, S. R. (2008). Distinctiveness and Memory: A Theoretical and Empirical Review, Learning and Memory: A Comprehensive Reference, 125-144. https://doi.org/10. $\underline{1016 / \mathrm{b} 978-012370509-9.00143-1}$ 
[3] Jones, S., \& Murphy, M. L. (2005). Using corpora to investigate antonym acquisition. International Journal of Corpus Linguistics, 10(3), 401-422. https://doi.org/10.1075/ijcl.10.3. 06jon.

[4] Jones, S. (2007). 'Opposites' in discourse: A comparison of antonym use across four domains. Journal of Pragmatics, 39(6), 1105-1119. https://doi.org/10.1016/j.pragma.2006.11. $\underline{019}$

[5] Murphy, M. L., \& Jones, S. (2008). Antonyms in children's and child-directed speech. First language, 28(4), 403-430. https://doi.org/10.1177/0142723708091047

[6] Zhuanglin, H. (2001). Linguistics. A Course Book. Beijing: Beijing University Press.

[7] Finegan, E. (2014). Language: Its structure and use. ( $4^{\text {th }}$ ed). Boston: Thomson Wadsworth, 2004.

[8] Murphy, M. L. (2003). Semantic relations and the lexicon: Antonymy, synonymy and other paradigms. Cambridge University Press. https://doi.org/10.1017/cbo9780511486494

[9] Jones, S., Murphy, M. L., Paradis, C., \& Willners, C. (2012). Antonyms in English: Construals, constructions and canonicity. Cambridge University Press. https://doi.org/10.1017/ cbo9781139032384

[10] Joshi, S. (2012). Affixal negation-direct, indirect and their subtypes. Syntaxe et semantique, (1), 49-63. https://doi.org/10.3917/ss.013.0049

[11] Paivio, A. (1991). Dual coding theory: Retrospect and current status. Canadian Journal of Psychology/Revue canadienne de psychologie, 45(3), 255. https://doi.org/10.1037/h00842 $\underline{95}$

[12] Alqahtani, M. (2015). The importance of vocabulary in language learning and how to be taught. International journal of teaching and education, 3(3), 21-34. https://doi.org/10.204 72/te.2015.3.3.002

[13] Gower, R., Phillips, D., \& Walters, S. (2005). Teaching Practice Handbook ( ${ }^{\text {rd }}$ ed). Oxford: Macmillan Education.

[14] Rohmatillah, R. (2014). A Study on Students' Difficulties in Learning Vocabulary. English Education: Jurnal Tadris Bahasa Inggris, 6(1), 75-93.

[15] Paul, P. V., \& O'Rourke, J. P. (1988). Multimeaning words and reading comprehension: Implications for special education students. Remedial and Special Education, 9(3), 42-52. https://doi.org/10.1177/074193258800900308

[16] Blachowicz, C. L., \& Fisher, P. (2004). Building vocabulary in remedial settings: Focus on word relatedness. Perspectives, 30(1), 1-21..

[17] Powell, W. R. (1986). Teaching vocabulary through opposition. Journal of Reading, 29(7), 617-621.

[18] Alanazi, M. (2017). On the production of synonyms by Arabic-speaking EFL learners. International Journal of English Linguistics, 7(3), 17-28. https://doi.org/10.5539/ijel.v7n3p17

[19] Alharbi, H. A. (2015). Improving Students' English Speaking Proficiency in Saudi Public Schools. International Journal of Instruction, 8(1), 105-116. https://doi.org/10.12973/iji.20 $\underline{15.818 \mathrm{a}}$

[20] Zibin, A., \& Altakhaineh, A. R. M. (2019). The effect of blended learning on the development of clause combining as an aspect of the acquisition of written discourse by Jordanian learners of English as a foreign language. Journal of Computer Assisted Learning, 35(2), 256-267. https://doi.org/10.1111/jcal.12327

[21] Altakhaineh, A. R. M., \& Zibin, A. (2017). The effect of incidental learning on the comprehension of English affixes by Arabic-speaking EFL learners: acquisition and application. Research in Language, 15(4), 405-423. https://doi.org/10.1515/rela-2017-0023

[22] Zhang, G. (2009). T-test: The good, the bad, the ugly, \& the remedy. Middle Grades Research Journal, 4(2). 
[23] Sadoski, M. (2005). A dual coding view of vocabulary learning. Reading \& Writing Quarterly, 21(3), 221-238.https://doi.org/10.1080/10573560590949359

[24] Shafipoor, M., Sarayloo, R., \& Shafipoor, A. (2016). Infographic (information graphic); a tool for increasing the efficiency of teaching and learning processes. International Academic Journal of Innovative Research, 3(4), 39-45.

\section{$7 \quad$ Authors}

Abdel Rahman Mitib Altakhaineh is Assistant Professor of English language and linguistics at Al Ain University of Science and Technology, UAE. He is currently the Head of English Department. His research interests lie in the areas of morphology, lexical semantics, morphosyntax, applied linguistics, and psycholinguistics. He has published research papers in several journals, including: Studia Linguistica, Lingua, Acta Linguistica Hungarica, Metaphor and the Social World, Journal of Computer Assisted Learning, Research in Language and Sage Open.

Maram Hajjo is English Language Teacher at Al-Andalus Private Academy, Al Ain, UAE. She obtained her MA in TESOL from Al Ain University of Science and Technology. Her research interests lie in the areas of applied linguistics, technology in learning and teaching and SLA.

Article submitted 2019-07-04. Resubmitted 2019-08-03. Final acceptance 2019-08-08. Final version published as submitted by the authors. 


\section{Appendix: Post-Test}

Next to each word, write the opposite word from the following choices

(straight - shallow - apart- dwarf- cowardly- taciturn- asleep- optimistic - crookedgenerous)

(1)

